\title{
Papers
}

\section{Fertility patterns after appendicectomy: historical cohort study}

Roland Andersson, Mats Lambe, Reinhold Bergström

\begin{abstract}
Objective To examine fertility patterns in women who had their appendix removed in childhood. Design Historical cohort study with computerised data and fertility data for this cohort and for an age matched cohort of women from the Swedish general population. The cohorts were followed to 1994. Setting General population.

Participants 9840 women who were under 15 years when they underwent appendicectomy between 1964 and 1983; 47590 control women.

Main outcome measures Diagnoses at discharge. Distributions of age at birth of first child among women with perforated and non-perforated appendix and women who underwent appendicectomy but were found to have a normal appendix compared with control women by using survival analysis methods. Parity distributions at the latest update of the registry were also examined.

Results Women with a history of perforated appendix had a similar rate of first birth as the control women (adjusted hazard ratio $0.95 ; 95 \%$ confidence interval 0.88 to 1.04 ) and had a similar distribution of parity at the end of follow up. Women who had had a normal appendix removed had an increased rate of first births $(1.48 ; 1.42$ to 1.54$)$ and on average had their first child at an earlier age and reached a higher parity than control women.

Conclusion A history of perforated appendix in childhood does not seem to have long term negative consequences on female fertility. This may have important implications for the management of young women with suspected appendicitis as the liberal attitude to surgical explorations with a subsequently high rate of removal of a normal appendix is often justified by a perceived increased risk of infertility after perforation. Women whose appendix was found to be normal at appendicectomy in childhood seem to belong to a subgroup with a higher fertility than the general population.
\end{abstract}

\section{Introduction}

Surgical exploration for suspected appendicitis is the most common acute abdominal operation in children and young adults. In $20 \%$ to $30 \%$ of these explorations the appendix is not inflamed. ${ }^{1}$ The long term morbidity after appendicitis and removal of a normal appendix has not been studied much. Apart from an increased risk of intestinal obstruction ${ }^{2}$ it is commonly thought that a perforated appendix may result in tubal dysfunction because of peritoneal adhesions after inflammation and a subsequent increased risk for extrauterine pregnancy and female infertility. With reference to this risk surgeons have been recommended to "operate early enough to sacrifice some degree of diagnostic accuracy." 3 The same opinion has been expressed by others. ${ }^{4-7}$ A liberal use of laparoscopy in women with suspected appendicitis has also been recommended because of fear of tubal dysfunction due to postsurgical peritoneal adhesions after conventional open appendicectomy. ${ }^{8-11}$

There is, however, no firm evidence for these recommendations. With inconsistent results, fertility after appendicitis has been examined in a few follow up studies of a small number of patients operated on for a perforated appendix and in case-control studies of patients who were investigated for perceived infertility. ${ }^{11-14}$ Fertility after removal of a normal appendix has not been analysed previously. We compared fertility patterns in three cohorts of women who had undergone appendicectomy with a discharge diagnosis of perforated, non-perforated, and normal appendix with that in a cohort of control women matched for age.

\section{Methods}

\section{Participants}

We identified all women in the Swedish Hospital Inpatient Registry who underwent appendicectomy before the age of 15 years between 1964 and 1983. The inpatient registry contains information on date and type of each operation and the discharge diagnosis for patients treated in somatic care wards in Swedish hospitals.

On the basis of the discharge diagnosis the patients were divided into three groups: non-perforated appendix, perforated appendix, and normal appendix at exploration. Patients with a diagnosis indicating another disease that needed surgical treatment were excluded as these operations were necessary explorations. Patients with a gynaecological condition at operation were also excluded as these diseases could affect fertility.

The study included 9840 women who had been operated on before they were 15 years old and who
Division of Surgery, University Hospital, Linköping, Sweden Roland Andersson, senior registrar

Department of Medical Epidemiology, Karolinska Institute, Stockholm, Sweden Mats Lambe, lecturer

Department of Statistics, Uppsala University, Uppsala, Sweden

Reinhold Bergström, professor

Correspondence to: Dr Andersson, Department of Surgery, Ryhov Hospital, S-551 85 Jönköping, Sweden roland.andersson@ ryhov.ltjkpg.se

BMJ 1999;318:963-7 
Table 1 Distribution of end points at end of follow up in women according to findings at appendicectomy in childhood. Values are numbers (percentages) of women

\begin{tabular}{lcccc} 
End point & $\begin{array}{c}\text { Normal } \\
\text { appendix } \\
(\mathbf{n = 3 1 2 6 )}\end{array}$ & $\begin{array}{c}\text { Appendix not } \\
\text { perforated } \\
(\mathbf{n = 5 8 1 5 )}\end{array}$ & $\begin{array}{c}\text { Perforated } \\
\text { appendix } \\
(\mathbf{n = 8 9 9})\end{array}$ & $\begin{array}{c}\text { Controls } \\
(\mathbf{n}=\mathbf{4 7 5 9 0 )}\end{array}$ \\
\hline Birth of child & $2294(73.4)$ & $3852(66.2)$ & $553(61.5)$ & $30268(63.6)$ \\
\hline Emigrated & $65(2.1)$ & $128(2.2)$ & $19(2.1)$ & $1080(2.3)$ \\
\hline Death & $15(0.5)$ & $26(0.5)$ & $3(0.3)$ & $218(0.5)$ \\
\hline Nulliparity & $752(24.1)$ & $1809(31.1)$ & $324(36.0)$ & $16024(33.7)$ \\
\hline
\end{tabular}

were aged 15 years at the start of follow up and were nulliparous (22 patients were excluded because they had died, emigrated, or given birth after the operation but before the age of 15). The discharge diagnosis was appendicitis in 6714 patients $(899$ (13\%) with perforated appendix and 5815 without), while 3126 patients $(32 \%)$ had a normal appendix removed.

For each patient we selected five controls at random from the women in the Swedish Fertility Registry who had the same birth date as the patients. This nationwide registry provides fertility data for all women who were Swedish citizens in 1960 or who were born in Sweden since 1960. Information regarding the date of all live births and the date of emigration or death was obtained for the patients and the controls. The latest update of the registry for the purpose of this study was 31 December 1995.

For technical reasons the 49200 randomly selected controls were matched on the birth date whereas the patients were eligible first at age 15 . Between birth and age 15 some control women had emigrated $(n=625)$, died $(n=979)$, or given birth $(n=6)$. These 1610 women were excluded. Thus the final analysis included 9840 cases and 47590 controls.

All women were followed from 15 years old until date of first birth. Nulliparous women were censored at date of emigration or death or at the latest update of the registry. The childbearing pattern of the women was also assessed from the distribution of parity at the date of emigration or death or at the latest update of the registry.

\section{Statistical methods}

The dependent variable considered in most analyses was age at first birth. We analysed this variable by survival methods because of the varying length of follow up. Simple comparisons between groups were performed on the basis of survival curves computed by the Kaplan-Meier method. These curves describe the cumulative proportion of primiparous women at each age, taking into account the varying length of follow up. Tests for the equality of such curves were carried out by the log rank test. Age specific rates of first birth were calculated by using the life table approach.

Cox proportional hazards regression models were used to compare the average age specific rates of first birth in different groups of women. In the multivariate models the hazard ratio was adjusted for any differences in the distribution of the covariates between the groups of women. The matching variable of birth date was included explicitly as an explanatory variable in these analyses. The results are given as hazard ratios (95\% confidence intervals). A ratio larger than 1 implies a larger probability of an early first birth than in the reference group.
The standard Cox model assumes proportional hazards at all ages for the treated groups or in the present case the same ratios of rate of first birth at all ages compared with the reference group. Inspection of the curves of the age specific rates of first birth showed that this assumption was not fulfilled. Therefore we also obtained estimates in three different age intervals that allowed different relative birth rates among treated groups.

Because of the long study period we also analysed the influence of year of operation. Separate analysis were performed for operations that had been performed in 1964-8, 1969-73, 1974-8, and 1979-84 with adjustment for year of birth. Age at operation was deliberately omitted from these analysis because with data covering short periods there will be a strong correlation between year of birth and age at operation, which makes it unsuitable to include both variables in the same model.

The variable parity (number of children at latest registry update) is dependent on age (birth year) and length of follow up. Therefore formal testing of differences between groups was performed after adjustment for birth year (standard regression analysis for continuous variables and logistic regression for dichotomous variables). In these regressions we also adjusted for lost years of follow up because of emigration or death by the inclusion of the length of follow up in the models.

\section{Results}

The distribution of the end points in the cohorts-that is, birth of a child or censoring - and the reason for censoring are given in table 1 . The mean age at the end of follow up was 31.6 years.

\section{Age at first birth}

Women with a history of perforated appendix in childhood and the control women had similar fertility, as shown from the Kaplan-Meier plots of the cumulative proportion of primiparous women (fig 1 ; $\log$ rank test $\mathrm{P}=0.20$ ). Women who had had a normal appendix removed or had a non-perforated appendix tended to have their first child at an earlier age than control women (fig 1 ; $\log$ rank test $\mathrm{P}<0.001$ ). The higher rate

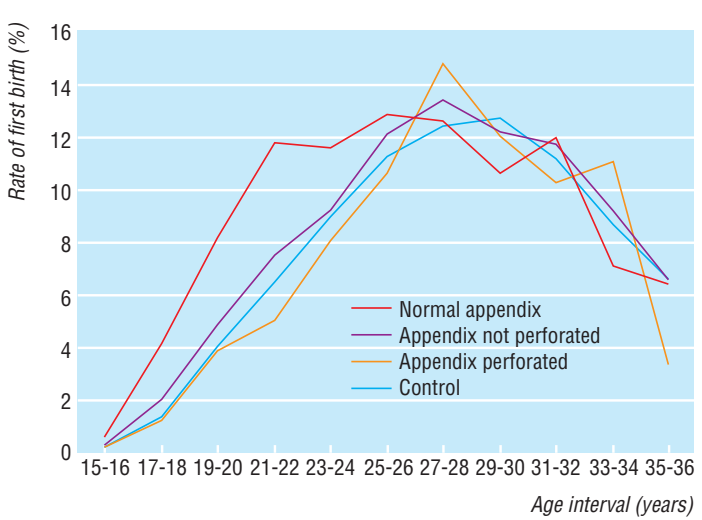

Fig 1 Kaplan-Meier plot of cumulative proportion of parous women at each age for 9840 women who underwent appendicectomy before age 15 and 47590 age matched controls 


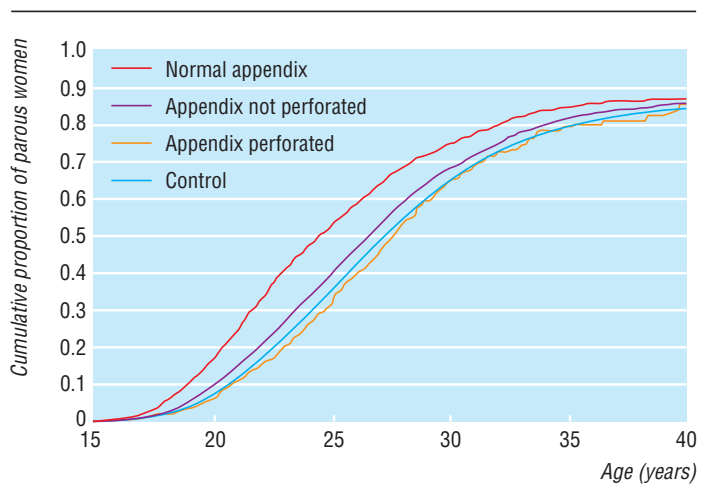

Fig 2 Age specific rates of first birth among women who underwent appendicectomy before age 15 and among age matched controls according to life table analysis. Figure shows average birth rate in a given 2 year age interval

of the first birth in the women who had had a normal appendix removed was present only before the age of 25 years, as shown by the age specific rates of first birth (fig 2).

\section{Multivariate analysis of fertility}

The influence of the diagnosis at operation, the women's year of birth, and age at operation was analysed with univariate and multivariate Cox proportional hazards regression models (table 2). Women with perforated appendix had a similar fertility as the control women while women with a normal appendix or non-perforated appendix gave birth to their first child at a higher rate.

Differences in fertility at different ages of follow up The ratio of the age specific rates of first birth of the women who underwent operation and the control women were not proportional at all ages (fig 2). We therefore also performed separate analyses for the age intervals $15-19,20-24$, and $\geqslant 25$ years at follow up (table 3). Relative to the control women, patients with a history of perforated appendix had a (non-significant) lower birth rate at 15-19 years and at 20-24 years but not at age $\geqslant 25$ years.
Table 2 Fertility after appendicectomy compared with age matched controls according to Cox proportional hazards regression analysis of rate of first birth. Results compare average rates of first birth expressed as hazard ratios. Differences in birth rates according to diagnosis at operation were adjusted for year of birth and age at operation. Values are hazard ratios (95\% confidence intervals); P values

\begin{tabular}{lrcc}
$\begin{array}{l}\text { Factor } \\
\text { Diagnosis at operation: }\end{array}$ & $\begin{array}{c}\text { No of } \\
\text { women }\end{array}$ & Univariate analysis & Multivariate analysis \\
\hline Control & 47590 & 1.00 & 1.00 \\
\hline Normal appendix & 3126 & $1.48(1.42$ to 1.54$) ;<0.001$ & $1.48(1.42$ to 1.54$) ;<0.001$ \\
\hline Appendix not perforated & 5815 & $1.11(1.07$ to 1.15$) ;<0.001$ & $1.11(1.07$ to 1.15$) ;<0.001$ \\
\hline Perforated appendix & 899 & $0.95(0.87$ to 1.03$) ; 0.20$ & $0.95(0.88$ to 1.04$) ; 0.26$ \\
\hline Year of woman's birth: & & & 1.00 \\
\hline Before 1960 & 11404 & 1.00 & $0.87(0.84$ to 0.89$) ;<0.001$ \\
\hline $1960-4$ & 17648 & $0.87(0.85$ to 0.89$) ;<0.001$ & \\
\hline $1965-9$ & 23421 & $0.82(0.79$ to 0.84$) ;<0.001$ & $0.82(0.79$ to 0.84$) ;<0.001$ \\
\hline After 1969 & 4957 & $0.74(0.70$ to 0.78$) ;<0.001$ & $0.75(0.71$ to 0.79$) ;<0.001$ \\
\hline Age at operation (years): & & & 1.00 \\
\hline$<11$ & 9170 & & 1.00 \\
\hline 11 & 10968 & $0.95(0.92$ to 0.99$) ;<0.007$ & $0.98(0.94$ to 1.01$) ; 0.21$ \\
\hline 12 & 11883 & $0.95(0.92$ to 0.98$) ;<0.003$ & $0.98(0.95$ to 1.01$) ; 0.24$ \\
\hline 13 & 11966 & $0.98(0.95$ to 1.02$) ; 0.33$ & $1.00(0.97$ to 1.03$) ; 0.96$ \\
\hline 14 & 13443 & $1.01(0.97$ to 1.04$) ; 0.75$ & $1.01(0.98$ to 1.05$) ; 0.47$ \\
\hline
\end{tabular}

In the younger age groups women who had had a normal appendix removed gave birth to their first child at a higher rate compared with control women. From age 25 there was no difference between cases and controls. Patients with non-perforated appendix also had an increased birth rate until the age of 25 years and no difference thereafter. As expected, women belonging to younger birth cohorts had a lower rate of first births (tables 2 and 4). Age at operation had no influence on the rate of first birth (tables 2 and 3).

\section{Influence on fertility of year of operation}

The analysis based on year of operation produced stable results (table 4). The hazard ratios associated with perforated appendix were close to 1 in all periods and not significantly differently different from 1 . Results for other groups were also quite similar over time. The slightly higher hazard ratio in the most recent period for women who had had a normal appendix removed may partly be due to the shorter follow up for these patients.

Table 3 Multivariate Cox proportional hazards analysis of rate of first birth in age groups 15-19, 20-24, and $\geqslant 25$ years at follow up. Differences in birth rate according to diagnosis at operation adjusted for year of woman's birth and age at operation. Values are adjusted hazard ratios (95\% confidence intervals); $P$ values

\begin{tabular}{|c|c|c|c|}
\hline Factor & $15-19$ years & $20-24$ years & $\geqslant 25$ years \\
\hline \multicolumn{4}{|l|}{ Diagnosis at operation: } \\
\hline Control & 1.00 & 1.00 & 1.00 \\
\hline Normal appendix & 2.57 (2.34 to 2.83 ); <0.001 & 1.63 (1.53 to 1.73 ); <0.001 & 1.03 (0.95 to 1.11$) ; 0.51$ \\
\hline Appendix not perforated & 1.37 (1.24 to 1.50$) ;<0.001$ & 1.11 (1.06 to 1.17$) ;<0.001$ & 1.05 (0.99 to 1.11$) ; 0.051$ \\
\hline Perforated appendix & 0.84 (0.63 to 1.12$) ; 0.23$ & 0.89 (0.78 to 1.01$) ; 0.08$ & 1.03 (0.92 to 1.16$) ; 0.59$ \\
\hline \multicolumn{4}{|l|}{ Year of woman's birth: } \\
\hline Before 1960 & 1.00 & 1.00 & 1.00 \\
\hline $1960-4$ & 0.53 (0.49 to 0.57$) ;<0.001$ & $0.77(0.74$ to 0.81$) ;<0.001$ & 1.07 (1.03 to 1.11$) ;<0.001$ \\
\hline $1965-9$ & 0.39 (0.36 to 0.43 ); $<0.001$ & 0.83 (0.79 to 0.86$) ;<0.001$ & 0.97 (0.92 to 1.01$) ; 0.13$ \\
\hline After 1969 & 0.53 (0.47 to 0.60$) ;<0.001$ & $0.71(0.66$ to 0.76$) ;<0.001$ & 0.82 (0.66 to 1.01$) ; 0.06$ \\
\hline \multicolumn{4}{|l|}{ Age at operation (years): } \\
\hline$<11$ & 1.00 & 1.00 & 1.00 \\
\hline 11 & 1.00 (0.90 to 1.11$) ; 0.96$ & 0.95 (0.90 to 0.99$) ;<0.04$ & 1.01 (0.95 to 1.06$) ; 0.85$ \\
\hline 12 & 0.99 (0.89 to 1.10$) ; 0.88$ & 0.94 (0.89 to 0.99$) ;<0.02$ & 1.02 (0.97 to 1.07$) ; 0.47$ \\
\hline 13 & 1.08 (0.98 to 1.19$) ; 0.14$ & 0.97 (0.92 to 1.02$) ; 0.27$ & 1.01 (0.96 to 1.06$) ; 0.73$ \\
\hline 14 & 1.07 (0.97 to 1.18$) ; 0.16$ & 0.96 (0.91 to 1.01$) ; 0.08$ & 1.05 (1.00 to 1.10$) ;<0.05$ \\
\hline
\end{tabular}


Table 4 Multivariate Cox proportional hazards analysis of rate first birth in patients operated on in four periods between 1964 and 1984. Values are adjusted ${ }^{*}$ hazard ratios (95\% confidence intervals); $P$ values

\begin{tabular}{|c|c|c|c|c|}
\hline Factor & $1964-8$ & $1969-73$ & $1974-8$ & 1979-84 \\
\hline \multicolumn{5}{|l|}{ Diagnosis at operation: } \\
\hline Control & 1.00 & 1.00 & 1.00 & 1.00 \\
\hline Normal appendix & 1.33 (1.18 to 1.50$) ;<0.001$ & $1.34(1.22$ to 1.46$) ;<0.001$ & 1.46 (1.36 to 1.57$) ;<0.001$ & 1.72 (1.59 to 1.86$) ;<0.001$ \\
\hline Appendix not perforated & 1.13 (1.03 to 1.24$) ;<0.008$ & 1.07 (0.99 to 1.15$) ; 0.083$ & 1.08 (1.02 to 1.15$) ;<0.006$ & $1.17(1.10$ to 1.24$) ;<0.001$ \\
\hline Perforated appendix & 0.95 (0.75 to 1.19 ); 0.650 & 1.04 (0.87 to 1.25$) ; 0.656$ & 0.95 (0.82 to 1.09 ); 0.447 & 0.89 (0.76 to 1.05$) ; 0.165$ \\
\hline \multicolumn{5}{|l|}{ Year of woman's birth: } \\
\hline Before 1960 & 1.16 (1.06 to 1.28$) ;<0.001$ & 1.12 (1.22 to 1.46$) ;<0.001$ & 1.07 (0.95 to 1.21$) ; 0.234$ & - \\
\hline $1960-4$ & 1.00 & 1.00 & 1.00 & 1.00 \\
\hline $1965-9$ & - & 1.04 (0.92 to 1.18$) ; 0.528$ & 0.97 (0.93 to 1.01$) ; 0.143$ & 0.88 (0.79 to 0.97$) ;<0.02$ \\
\hline After 1969 & - & - & 0.77 (0.57 to 1.02$) ; 0.072$ & $0.81(0.73$ to 0.91$) ;<0.001$ \\
\hline
\end{tabular}

*Adjusted for year of woman's birth.

\section{Number of children at end of follow up}

The mean parity at the latest update of the fertility registry was higher in women with normal appendix or non-perforated appendix compared with the controls (1.61 and 1.36 v $1.27 ; \mathrm{P}<0.001)$. Women with perforated appendix had a similar number of children as the control women (1.21 $v 1.27 ; \mathrm{P}=0.38)$.

The similar fertility among women with a history of perforated appendix and the control women is also shown from the similar proportions of childless women $(38.5 \% v 36.4 \% ; \mathrm{P}=0.48)$ and of women with three or more births $(13.6 \% v 14.8 \% ; \mathrm{P}=0.63)$ (table 4$)$. Compared with the controls, nulliparity was less common among women with a history of non-perforated appendix $(33.8 \%)$ and removal of normal appendix $(26.6 \%)$, while multiparity (parity $3+$ ) was more common $(16.5 \%$ and $23.1 \%$, respectively).

\section{Discussion}

Contrary to current opinion our study did not show long term adverse influences on fertility in women who had a history of a perforated appendix in childhood. On the basis of these results a liberal attitude to exploration in young women with suspected appendicitis and the subsequent high rate of unnecessary appendicectomies cannot be justified by an assumed increased risk of infertility after perforation.

The idea of an increased risk of infertility after perforated appendix dates back to 1932, when Bull wrote, "It is generally agreed, I suppose, that acute appendicitis may bring about sterility in women." ${ }^{15}$ Subsequent studies, however, have generated inconsistent results. ${ }^{11-14}$

The strength of the present study is the follow up design, the large number of patients, and the end points-the age specific and cumulative rates of first birth-which are more sensitive to subfertility than the

Table 5 Parity status at end of follow up according to diagnosis at appendicectomy compared with control women matched for age. Values are numbers (percentages) of women

\begin{tabular}{lcccc} 
Parity & $\begin{array}{c}\text { Normal appendix } \\
(\mathbf{n = 3 1 2 6 )}\end{array}$ & $\begin{array}{c}\text { Appendix not perforated } \\
\mathbf{( n = 5 8 1 5 )}\end{array}$ & $\begin{array}{c}\text { Perforated appendix } \\
(\mathbf{n}=\mathbf{8 9 9})\end{array}$ & $\begin{array}{c}\text { Controls } \\
(\mathbf{n}=\mathbf{4 7 5 9 0 )}\end{array}$ \\
\hline Nulliparous & $832(26.6)$ & $1963(33.8)$ & $346(38.5)$ & $17322(36.4)$ \\
\hline Parity 1 & $578(18.5)$ & $1077(18.5)$ & $173(19.2)$ & $8797(18.5)$ \\
\hline Parity 2 & $995(31.8)$ & $1814(31.2)$ & $258(28.7)$ & $14412(30.3)$ \\
\hline Parity 3 & $486(15.6)$ & $703(12.1)$ & $98(10.9)$ & $5492(11.5)$ \\
\hline Parity 4 & $181(5.8)$ & $191(3.3)$ & $18(2.0)$ & $1277(2.7)$ \\
\hline Parity 5+ & $54(1.7)$ & $67(1.2)$ & $6(0.7)$ & $290(0.6)$ \\
\hline
\end{tabular}

rates of perceived infertility, the end point in previous studies.

One potential drawback is the validity of the discharge diagnosis. This was assessed in a previous study of the Jönköping County Hospital inpatient registry, which is a part of the national registry and probably representative for the whole register. ${ }^{1}$ The diagnosis of appendicitis was false positive in $10 \%$ and false negative in $6 \%$. Misclassification is related mainly to appendicitis with non-perforated appendix, which needs to be verified with histopathological examination. The slightly increased fertility in those women with a diagnosis of non-perforated appendix may be related to the higher fertility among patients who had a normal appendix removed but were misclassified as having appendicitis without a perforated appendix. Misclassification bias is less likely for perforated appendix with its more evident preoperative diagnosis.

Fertility not only depends on the biological conditions for childbearing but also on sociological factors. An early and increased fertility is seen in women with short education and low socioeconomic status. ${ }^{16}$ This may be responsible for the increased fertility in women who had had a normal appendix removed. The socioeconomic risk factors have not been well studied, but psychological abnormalities are more common among women who undergo such operations. ${ }^{17-19}$

Removal of a normal appendix may also be a result of misdiagnosed ovulatory pain and may thus be a marker for well functioning ovaries. This explanation for the observed increased fertility is, however, less probable as the effect was seen also in the patients who had been operated on before 10 years of age - that is, before menarche.

We have previously shown that a liberal attitude to exploration among patients with suspected appendicitis does not prevent perforations..$^{20}$ In the present study we have shown that long term fertility in women is not adversely influenced after an operation for perforated appendix in childhood. The present results do not support the current recommendation of a liberal attitude to exploration in women with suspected appendicitis for the purpose of avoiding impaired fertility in the future.

We thank Sten Martinelle, Statistics Sweden, for the preparation of the datasets and preliminary data analysis.

Contributors: RA initiated the study, participated in the design, carried out the statistical analyses, and participated in writing the paper. ML participated in the design of the study, coordinated the registry linkage, and participated in writing the 
Key messages

- A history of perforated appendix in childhood does not seem to have an adverse effect on female fertility

- The current recommendations of a liberal attitude to exploration in women with suspected appendicitis cannot be justified on the grounds of pervention of infertility

paper. RB planned the statistical analyses and presentation of results, wrote the statistical section of the paper, and edited the manuscript. RA is the guarantor.

Funding: Committee for Research and Development, Jönköping County Council, Health Research Council in Southeast Sweden, Swedish Society for Medical Research, and Lion Foundation, Sweden.

Competing interests: None declared.

1 Andersson RE, Hugander A, Thulin AJ. Diagnostic accuracy and perforation rate in appendicitis: association with age and sex of the patient and with appendicectomy rate. Eur J Surg 1992;158:37-41.

2 Rääf LE. Causes of small intestinal obstruction. Acta Chir Scand 1969;135:67-72

3 Malt RA. The perforated appendix. N Engl J Med 1986;315:1546-7.

4 Hoffmann J, Rasmussen OO. Aids in the diagnosis of acute appendicitis BrJ Surg 1989;76:774-9.

Trimbos-Kemper T, Trimbos B, van Hall E. Etiological factors in tubal infertility. Fertil Steril 1982:37:384-8.
6 Wiig JN, Janssen Jr CW, Fuglesang P, Gjoen OI, Hansen HA, Thue G, et al. Infertility as a complication of perforated appendicitis. Late follow-up of a clinical series. Acta Chir Scand 1979;145:409-10.

7 Thompson WM, Lynn HB. The possible relationship of appendicitis with perforation in childhood to infertility in women. J Pediatr Surg 1971;6:458-61.

8 Kum CK, Ngoi SS, Goh PM, Tekant Y, Isaac JR. Randomized controlled trial comparing laparoscopic and open appendicectomy. Br J Surg 1993;80:1599-600

9 Spirtos NM, Eisenkop SM, Spirtos TW, Poliakin RI, Hibbard LT Laparoscopy-a diagnostic aid in cases of suspected appendicitis. Its use in women of reproductive age. Am J Obstet Gynecol 1987;156:90-4.

10 Jadallah FA, Abdul-Ghani AA, Tibblin S. Diagnostic laparoscopy reduces unnecessary appendicectomy in fertile women. Eur J Surg 1994;160:41-5.

11 Lalos O. Risk factors for tubal infertility among infertile and fertile women. Eur J Obstet Gynecol Reprod Biol 1988;29:129-36.

12 Mueller BA, Daling JR, Moore DE, Weiss NS, Spadoni LR, Stadel BV, et al. Appendectomy and the risk of tubal infertility. $N$ Engl $J$ Med $1986 ; 315: 1506-8$.

13 Puri P, McGuinness EP, Guiney EJ. Fertility following perforated appendicitis in girls. J Pediatr Surg 1989;24:547-9.

14 Geerdsen JP. Sterilitet-senkomplikation til appendicitis acuta perforata hos piger? Nord Med 1988;103:62-3.

15 Bull $\mathrm{P}$. What part is played by acute appendicitis in the causation of sterility in young girls and women? Acta Chir Scand 1932;71:155-65.

16 Källén B. Population characteristics that may confound analysis. In: Källén B. Epidemiology of human reproduction. Florida: CRC Press, 1988: 107-23.

17 Vassilas CA. Parasuicide and appendicectomy. Br J Psychiatry 1988; 152:706-9.

18 Canton G, Santonastaso P, Fraccon IG. Life events, abnormal illness behavior, and appendectomy. Gen Hosp Psychiatry 1984;6:191-5.

19 Joyce PR, Walshe JW, Bushnell JA, Morton JB. Readmissions to hospital after appendicectomy for non-specific abdominal pain. Aust N Z J Surg 1981;51:465-7.

20 Andersson R, Hugander A, Thulin A, Nystrom PO, Olaison G Indications for operation in suspected appendicitis and incidence of perforation. BMJ 1994;308:107-10

(Accepted 29 January 1999)

\section{Ethnic differences in incidence of stroke: prospective study with stroke register}

Judith A Stewart, R Dundas, R S Howard, A G Rudd, C D A Wolfe

\section{Abstract}

Objective To identify ethnic differences in the incidence of first ever stroke.

Design A prospective community stroke register (1995-6) with multiple notification sources. Pathological classification of stroke in all cases was based on brain imaging or necropsy data. Rates were standardised to European and world populations and adjusted for age, sex, and social class in multivariate analysis.

Setting A multi-ethnic population of 234533 in south London, of whom $21 \%$ are black.

Results 612 strokes were registered. The crude annual incidence rate was 1.3 strokes per 1000 population per year $(95 \%$ confidence interval 1.20 to $1.41)$ and 1.25 per 1000 population per year (1.15 to 1.35) age adjusted to the standard European population. Incidence rates adjusted for age and sex were significantly higher in black compared with white people $(\mathrm{P}<0.0001)$, with an incidence rate ratio of 2.21 (1.77 to 2.76). In multivariable analysis increasing age $(\mathrm{P}<0.0001)$, male sex $(\mathrm{P}<0.003)$, black ethnic group $(\mathrm{P}<0.0001)$, and lower social class $(\mathrm{P}<0.0001)$ in people aged $35-64$ were independently associated with an increased incidence of stroke. Conclusions Incidence rates of stroke are higher in the black population; this is not explained by confounders such as social class, age, and sex. Ethnic differences in genetic, physiological, and behavioural risk factors for stroke require further elucidation to aid development of effective strategies for stroke prevention in multi-ethnic communities.

\section{Introduction}

Incidence rates of first stroke in different white populations worldwide have been determined..$^{1-3}$ A study in the United States showed a twofold increase in the incidence in one black population, ${ }^{4}$ but no data are available on black populations in Europe. Mortality from stroke, however, is higher among black people than white people in the United Kingdom and the United States. ${ }^{56}$ In Britain, Caribbean immigrants have the highest mortality from stroke, with some evidence that this is due to increased incidence rather than case fatality. ${ }^{78}$ Previous studies in black populations are difficult to interpret because of methodological inconsistencies. $^{79}$

In the United Kingdom there are targets to reduce mortality from stroke. ${ }^{10}$ These are difficult to attain without accurate incidence data. In 1989-90 a community stroke register in south London identified that ethnicity was associated with incidence of stroke in residents aged under 75 years. ${ }^{11}$ The south London stroke register was established to investigate ethnic differences in the natural history of stroke. We present incidence data for the first 2 years (1 January 1995 to 31 December 1996).
Department of Public Health Sciences, Guy's, King's College, and St Thomas's Schoo of Medicine, 5 th Floor, Capital House, London SE1 3QD

Judith A Stewart, lecturer in stroke medicine

R Dundas, research associate C D A Wolfe, reader in public health medicine

Department of Neurology,

St Thomas's

Hospital, London

SE1 5EH

R S Howard, consultant neurologist

Stroke Unit, St Thomas's Hospital, London SE1 5EH

A G Rudd, consultant physician Correspondence to: Dr Wolfe c.wolfe@umds. ac.uk

BMJ 1999;318:967-71 